7. Reprod. Fert. (1971) 25, 201-210

\title{
AN ANGIOGRAPHIC STUDY OF THE STRUCTURE AND FUNCTION OF THE UTERINE AND MATERNAL PLACENTAL VASCULATURE IN THE RABBIT
}

\author{
A. M. GARTER, J. GÖTHLIN AND T. OLIN \\ Institute of Zoophysiology, University of Lund, and \\ Department of Roentgendiagnostics, University Hospital, Lund, Sweden
}

(Received 24th Fune 1970)

\begin{abstract}
Summary. The uterine and maternal placental vasculature of the rabbit has been studied by serial angiography after selective catheterization of the urogenital artery or the corresponding vein and in specimens injected with barium sulphate suspension and gelatin. The uterus is supplied with blood through long, spiral arteries. Some of these perfuse the myometrium whilst others enter the placentae, opening into large arterial sinuses which supply the labyrinth through wide efferent vessels. It is suggested that blood pressure is reduced and pulse pressure damped during passage of the blood through the spiral arteries and that the function of the sinuses is to raise the lateral pressure and reduce the linear velocity, so that a slow even perfusion of the placental labyrinth can be achieved. Cross connections between the spiral arteries and a plexus of finer arterial vessels beneath each placenta enable redistribution of blood flow between the myometrium and placentae. In addition, there are probably arteriovenous anastomoses in pregnant as well as non-pregnant uteri. A sphincter mechanism in the placental feeding arteries is postulated to prevent intrapartum haemorrhage after delivery of the placentae and possibly to regulate maternal placental blood flow during pregnancy. Total uterine blood flow was estimated to be about $30 \mathrm{ml} / \mathrm{min}$. Circulation time through the myometrium was much less than that through the placenta.
\end{abstract}

\section{INTRODUCTION}

Experimental studies of the uteroplacental circulation can conveniently be performed by angiography in the rabbit (Garter, Göthlin \& Bengtsson, 1968). In the course of the present work, we have improved upon our original angiographic technique and supplemented it by registration of intrauterine pressure and maternal circulatory parameters. Additional information has been obtained by X-ray examination of pregnant uteri injected with barium sulphate suspension and gelatin.

This paper describes our current angiographic techniques and principal morphological findings, together with an estimation of the total uterine blood 
flow and observations upon the circulation times through the rabbit myometrium and placenta.

\section{MATERIALS AND METHODS}

Twenty white rabbits of the Swedish Land race were studied at known stages of pregnancy from 20 to 29 days post coitum (full term occurs at 31 to 32 days). Examinations were made both in the living animal and at post mortem in injected specimens.

\section{Serial angiography in anaesthetized rabbits}

General anaesthesia was obtained with intravenous pentobarbitone sodium (mebumalnatrium 6\%, ACO, Sweden) and maintained at a constant level throughout the examination. For arteriographic studies, the tip of a radioopaque polyethylene catheter (OPP 60, Portex, England, o.d./i.d.-1.22 $\mathrm{mm} / 0.76 \mathrm{~mm}$ ) was tapered by pulling in hot air and the tip portion was slightly bent by moulding in hot air. Following a cut-down on to a femoral artery, the catheter was introduced and the tip placed in the ipsilateral urogenital artery. A similar procedure was followed for retrograde phlebography, except that the catheter used was of radio-opaque polyvinyl chloride (RO 1, Portex, o.d./i.d.-1.60/0.85 mm) and was placed in the mouth of the corresponding vein or advanced into one of the major branches of the uterine vein.

The catheters were positioned during fluoroscopy, using an X-ray tube with a $0 \cdot 3-\mathrm{mm}$ focus, two-fold geometrical magnification and an image intensifier vidicon system enabling a further two-fold magnification electronically. Serial angiography was made with the same geometrical enlargement, using an automatic film changer with high definition screens. The exposure was about $70 \mathrm{kV}$ and $5 \mathrm{mAs}(0.04 \mathrm{sec})$ when rapid polyester base film was employed. Film-focus distance was $90 \mathrm{~cm}$. Usually a series consisted of eight films at intervals of 1 $\mathrm{sec}$, followed by a further seven films at intervals of $5 \mathrm{sec}$, but the programme was varied when appropriate. The water soluble contrast medium (metrizoate methylglucamate, Isopaque Gerebral, Nyco, Norway) was injected with a high pressure syringe (VeReGe, Kistner, Sweden). The course of the contrast medium injections was recorded on a direct-writing polygraph so that the rate of injection could be exactly determined in each case. The polygraph also recorded film exposures and arterial pressure measured electromanometrically from a catheter in one common carotid artery. Thus, the timing of the films could be related precisely to the injections of contrast medium and to blood pressure changes.

The abdomen was opened and a catheter was introduced into the bladder through its wall to drain the urine. If this precaution was not taken, the bladder rapidly filled with the excreted contrast medium and obscured the lower abdomen.

Intrauterine pressure was recorded through a sponge-tipped, open-ended vinyl catheter (VX 020, Beckton Dickinson, U.S.A., o.d./i.d.- $0.9 \mathrm{~mm} / 0.5 \mathrm{~mm}$ ), filled with isotonic saline (Bengtsson, 1968). The catheter was inserted in the uterine horn on the same side as the angiography catheter through a small 
incision in the uterine wall. It was placed between the endometrium and foetal membranes with its tip opposite one of the placental implantation sites and secured by a purse-string suture, which also closed the incision. The abdominal wall was also sutured. The intrauterine pressure was measured electromanometrically and registered on a potentiometer writer (Servogor, Goertz, Austria). Film exposures were also registered on this record. We have previously made a careful study of the technique for registering changes of intrauterine pressure and established that each pressure wave recorded corresponds to a myometrial contraction over, or very near, the catheter tip (Garter \& Naaktgeboren, 1970; Carter, Naaktgeboren \& Van Zon-Van Wagtendonk, 1971).

\section{Estimation of uterine blood flow and circulation times}

The objective in selective angiography is temporarily to replace the blood flowing through a vessel by a bolus of contrast medium. If the rate of injection of the medium is below the rate of blood flow, the medium will be diluted by blood. Conversely, too high an injection rate will result in spilling of contrast medium to adjacent vessels. At a sufficient rate of injection, there will be no dilution at systole and only slight spilling at diastole. The rate of blood flow will then approximate to the recorded rate of injection of contrast medium. This principle has been applied to determine renal blood flow by angiography in rabbits (Olin \& Redman, 1966) and is used here to estimate the rate of blood flow in the urogenital artery.

Important information can be obtained by studying the time required for contrast medium to traverse various segments of the uteroplacental vasculature. The most instructive indices were the times taken for first filling of placental sinuses, complete emptying of the spiral arteries and first filling of the uterine veins. Wherever possible, distinction was made between those veins which drain the placentae and those which drain only the uterine wall.

\section{Radiography of post-mortem uteri}

The animal was given a rapid drip infusion of isotonic saline through a catheter in an external jugular vein, the arterial catheters were opened, and the circulation of the rabbit was thereby rinsed. The animal was killed by an overdose of pentobarbitone sodium and the aorta was clamped. Thereafter, a mixture of fine-grained barium sulphate suspension (Micropaque ${ }^{\star}$, Damancey, England) and freshly prepared gelatin solution was injected through the angiography catheter. The filling of the vessels with this mixture was followed by fluoroscopy. When filling of the uterine and maternal placental vessels had been obtained, the injection was stopped. The vagina, uterus and adnexae were removed, reflux of the injected material being prevented by a large ligature, and the specimen was cooled in ice overnight. On the following day, the foetuses were carefully removed through an incision in the antimesometrial uterine wall and the specimen fixed in $10 \%$ formalin. It was later studied whole and after sectioning in various planes, using industrial X-ray film (Structurix D4, Gaevert, Belgium). The exposure used was about $50 \mathrm{kV}$ and the film-focus distance was $45 \mathrm{~cm}$. 


\section{RESULTS}

The arterial supply to each horn of the rabbit uterus (Text-fig. 1; PI. 1, Fig. 1) has been outlined in a previous publication (Carter et al., 1968). The main stem, referred to as the urogenital artery, arises at the bifurcation of the common iliac artery into the external and internal iliac arteries. It gives off ureteric and vesical arteries and the superior vaginal artery, the last itself dividing into

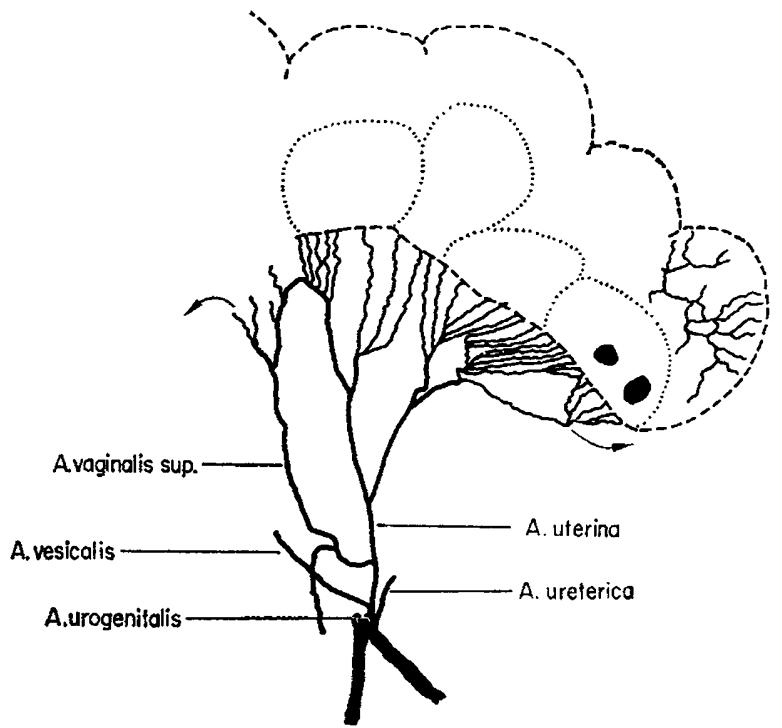

TEXT-pig. 1. Schematic drawing of the urogenital artery of the rabbit in mid-pregnancy. The broken line indicates the outline of the uterus and the dots delineate the placentae. A few myometrial vessels are shown and the placental sinuses are represented. The arrows indicate anastomoses with the contralateral superior vaginal artery and the ipsilateral ovarian artery.

caudal and cranial branches. The uterine artery proper runs in the broad ligament and there divides first into two large branches and then into numerous tortuous or spiral arteries, about $5 \mathrm{~cm}$ long and $0.5 \mathrm{~mm}$ in diameter. The branches of the uterine artery anastomose with branches from the ipsilateral ovarian and superior vaginal arteries.

\section{EXPLANATION OF PLATE 1}

Fic. 1. Contrast medium injected through a catheter inserted selectively in the urogenital artery of a rabbit near term. The uterine horn contains a single foetus, whose skeleton is well calcified. Arterial phase, showing superior vaginal and uterine arteries, spiral arteries, some myometrial arteries and placental arterial sinuses.

Fro. 2. Same as Fig. 1. Venous phase, showing contrast medium in the placental labyrinth (diffuse, opaque area) and placental veins.

Fig. 3. Parturient rabbit, 29 days post coitum. The angiogram shows two placentae with clearly discernible arterial sinuses, the one nearest the cervix is indicated by an arrow.

Fic. 4. Same as Fig. 3. New angiogram, shortly after delivery of one of the foetuses with its placenta. The more lateral foetus remains in position and its placenta continues to receive maternal blood. At the implantation site of the delivered placenta (arrow), there is an area of opacity, probably corresponding to the plexus of vessels seen in Pl. 3, Fig. 12. No leakage of contrast medium into the uterine lumen occurred. 
PLIILE 1
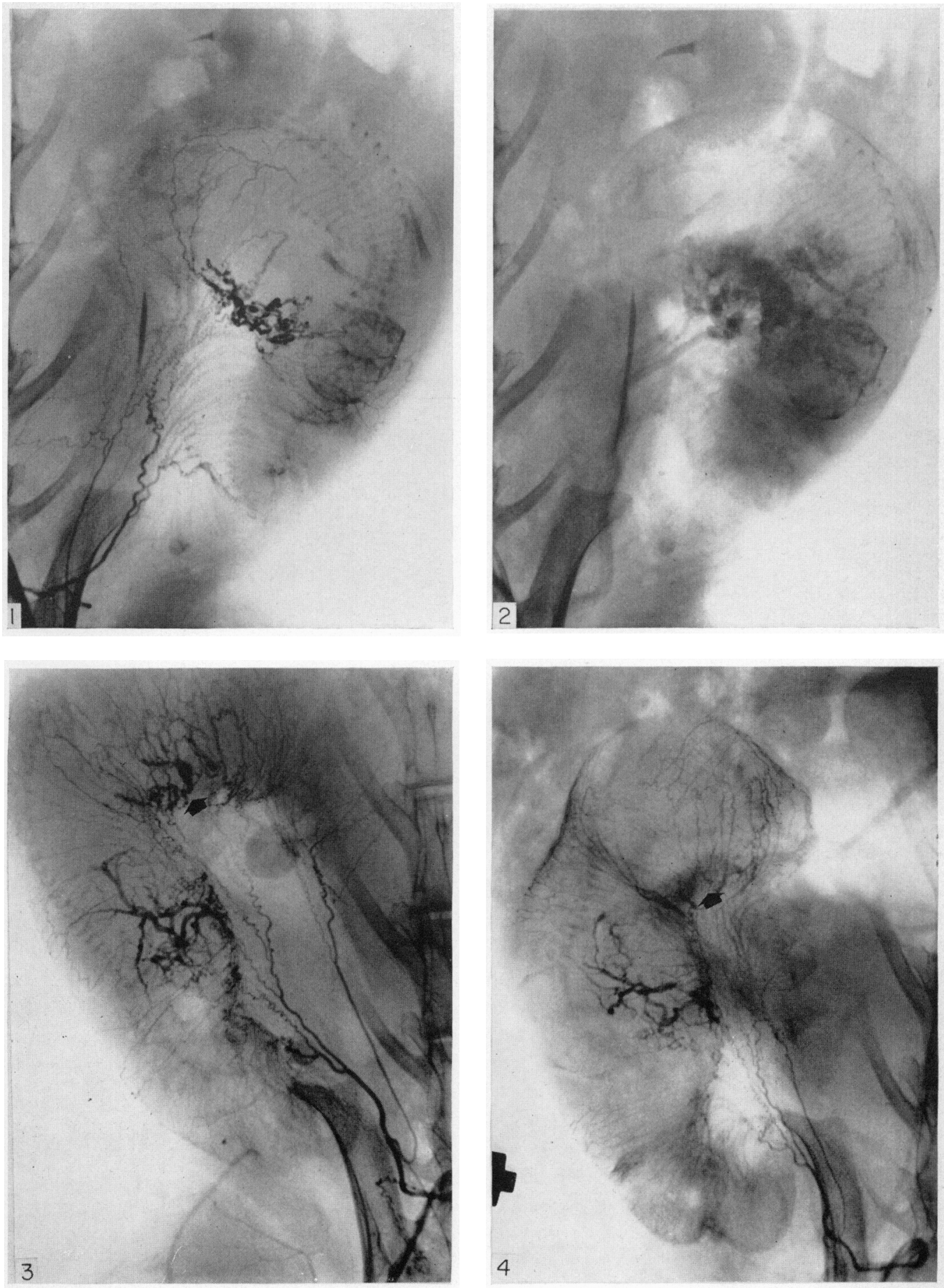

(Facing p. 204) 
PLATE 2
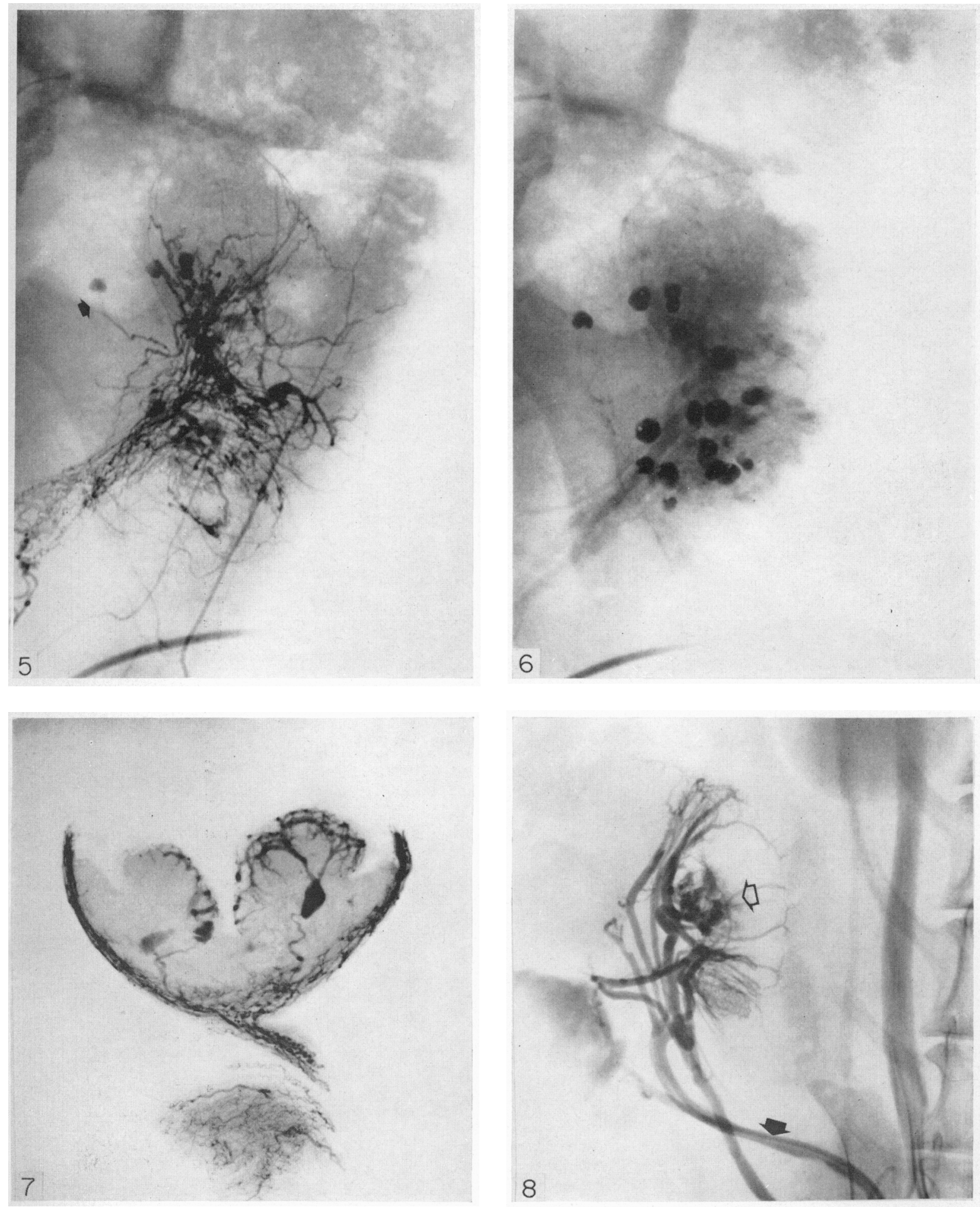

(Facing p. 205) 
The spiral arteries frequently divide again just before reaching the uterus and end in a straight portion which widens slightly. Some supply the myometrium, whilst others go to the placentae. There are cross connections between the arteries and a plexus of finer arteries beneath each placenta. This plexus is not part of the placenta, but is retained after delivery of the conceptus and continues to fill with contrast medium in subsequent angiographic examinations, without any leakage of the medium into the uterine lumen (Pl. 1, Figs. 3 and 4;

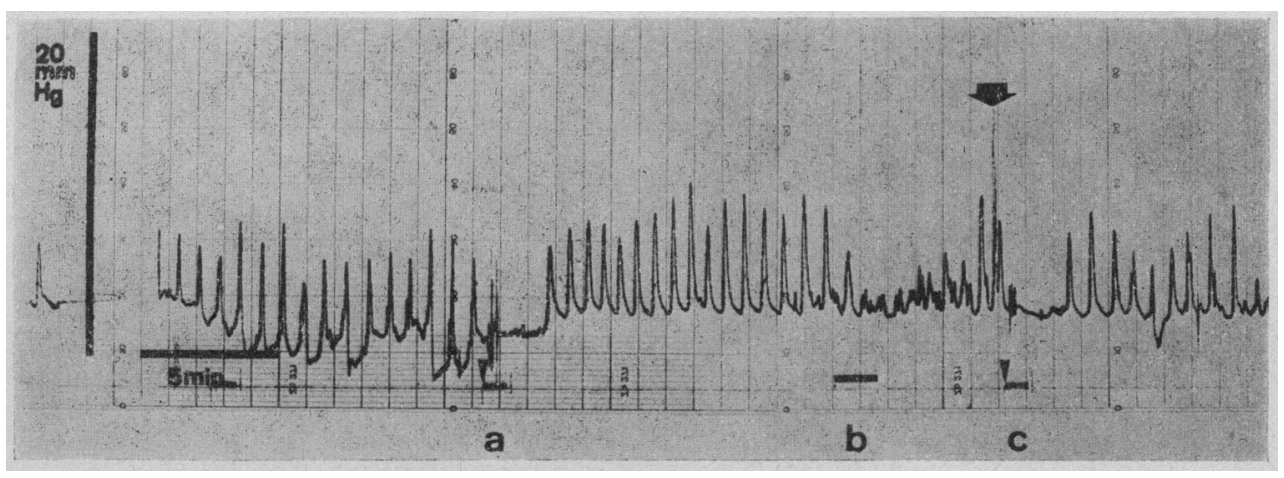

TEXT-FIG. 2. Intrauterine pressure recorded from the right uterine horn of a parturient rabbit. The lower trace indicates film exposures. (a) At start, angiography showed two placentae with functional maternal placental circulations (Pl. 1, Fig. 3). (b) The uterus was then observed in fluoroscopy and contrast medium injected several times, resulting in some suppression of uterine activity. Shortly afterwards, one of the two conceptuses was delivered (arrow). (c) Repeat angiography showed no leakage of contrast medium into the uterine lumen. The maternal placental circulation of the remaining conceptus continued to function normally (P1. 1, Fig. 4).

cf. Text-fig. 2). Similarly, it can be filled with barium sulphate suspension injected post partum ( $\mathrm{Pl}$. 3, Fig. 12). There is no prominent plexus in the nonpregnant horn of a unilaterally pregnant uterus (Pl. 3, Fig. 11).

The rabbit placenta consists of a foetal, trophoblastic portion and a maternal, decidual portion. The most prominent blood vessels are the large arterial sinuses, spherical to cylindrical in shape and 1 to $4 \mathrm{~mm}$ in diameter (Pl. 2, Figs. 5 and 6 ). They are few in number and each is supplied by a single feeding artery, which is a direct continuation of a spiral artery. This relation is seen

\section{EXPLANATION OF PLATE 2}

FIG. 5. Pregnant rabbit, 23 days post coitum. A large number of spiral arteries are filled with contrast medium. Some supply the myometrium whilst others, including that indicated by the arrow, are the feeding vessels to the placental arterial sinuses.

Fig. 6. Same as Fig. 5. Venous phase, showing pooling of the contrast medium in the placental arterial sinuses. Most sinuses contain a non-opaque area, representing the jet of blood from the feeding vessel.

FIG. 7. Thick section of a pregnant uterus, 24 days post coitum, injected with barium sulphate and gelatin. The sagittal section through one placenta shows a complete arterial unit-feeding vessel, arterial sinus and two efferent vessels-and parts of others. The spiral arteries in the mesometrium and the vascular plexus beneath the placenta are also demonstrated.

Fig. 8. Retrograde phlebography of the uterine vein in a pregnant rabbit, 20 days post coitum. Two large veins can be seen: one contains the catheter (closed arrow), whilst the other filled with contrast medium through venous anastomoses. The venous vessels of one placenta are also demonstrated (open arrow). 
most clearly in thick sections of injected specimens (Pl. 3, Fig. 9) but is also demonstrable in vivo (Pl. 2, Fig. 5).

The arterial sinuses are located in the decidual part of the placenta. They give off one or more efferent vessels, which rise through the trophoblastic portion of the placenta, branching profusely, especially at the foetal surface (Pl. 2, Fig. 7). The efferent arteries from each sinus together supply a discrete area of placenta, having a spider-like appearance in axial projection (Pl. 3, Fig. 10). These efferent vessels are wide relative to the narrow arteries feeding the sinuses. Measurement of a large but otherwise typical placental arterial unit (Pl. 4, Figs. 14 to 16) gave the following values for vessel diameters: feeding artery $0.7 \mathrm{~mm}$, arterial sinus $4.0 \mathrm{~mm}$ and efferent artery $1.8 \mathrm{~mm}$.

The efferent arteries empty into the channels of the placental labyrinth, through which the maternal blood flows in direct contact with the foetal trophoblast. The labyrinth is seen as a rather diffuse opaque area in serial angiography (Pl. 1, Fig. 2) and its channels do not admit barium sulphate particles (Pl. 2, Fig. 7). Blood flows from the labyrinth into collecting vessels and an extensive, irregular system of veins in the decidual part of the placenta. This system can be seen in angiograms made by injection of contrast material in the urogenital artery (Pl. 1, Fig. 2) but is best demonstrated by retrograde phlebography (Pl. 2, Fig. 8). The contrast medium used did not cross the placental barrier to enter the foetal circulation.

We have the impression that each placenta is drained by only one or two veins (Pl. 1, Fig. 2; Pl. 2, Fig. 8), which pass directly to the broad ligament through the uterine wall. Myometrial and placental veins join (Pl. 2, Fig. 8) to form a venous arcade with communication between the veins of the two uterine horns but, on each side, there are two principal veins with a relatively short common trunk that drains into the external iliac vein. The uterine veins are extremely wide in the rabbit and it has been calculated that they may contain up to $30 \mathrm{ml}$ blood during pregnancy, representing one-sixth of the total blood volume (Barcroft \& Rothschild, 1932).

When barium sulphate suspension is injected post mortem through the urogenital or uterine arteries, it usually appears in the veins. As already mentioned, the barium particles do not pass the placental labyrinth, so they must reach the

\section{EXPLANATION OF PLATE 3}

Fic. 9. Thick section from a pregnant uterus, 27 days post coitum, injected with barium sulphate suspension and gelatin. A spiral artery directly supplies a large placental arterial sinus.

Fig. 10. Section through a placenta parallel to its foetal surface. From a uterus injected with barium sulphate suspension and gelatin, 24 days post coitum. The efferent arteries of one arterial unit and parts of others are shown: each unit supplies a discrete area of the placenta.

Frg. 11. Sagittal section through the non-pregnant horn of a unilaterally pregnant uterus, injected with barium sulphate suspension and gelatin. Note the absence of a well developed vascular plexus.

Fig. 12. Sagittal section through the implantation site of a delivered conceptus. Barium sulphate suspension and gelatin were injected in the usual manner after the animal had been killed. The contrast material filled the vascular plexus in the uterine wall, but none leaked out into the uterine lumen. 
PLATE 3
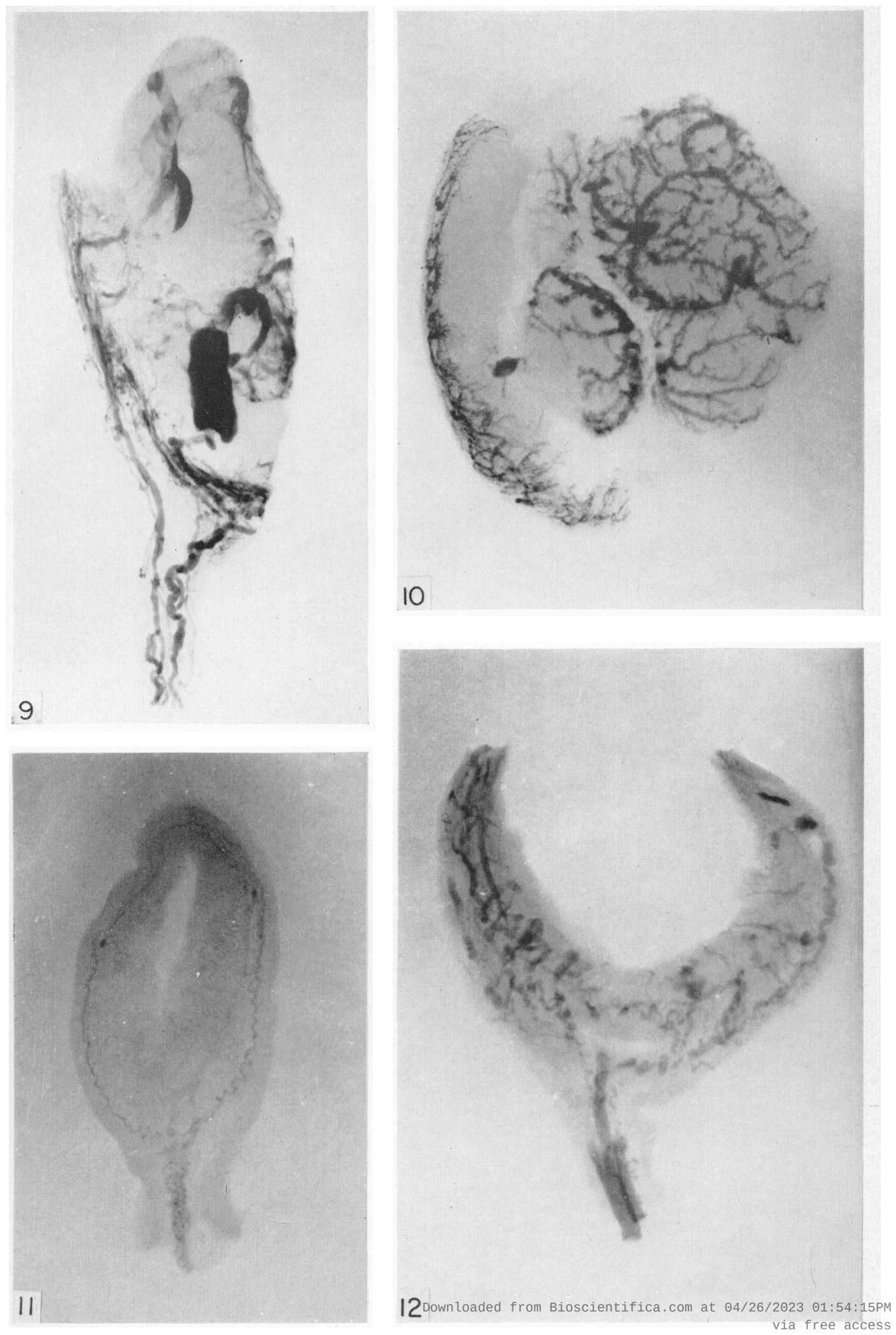

(Facing p. 206) 
PLATE 4
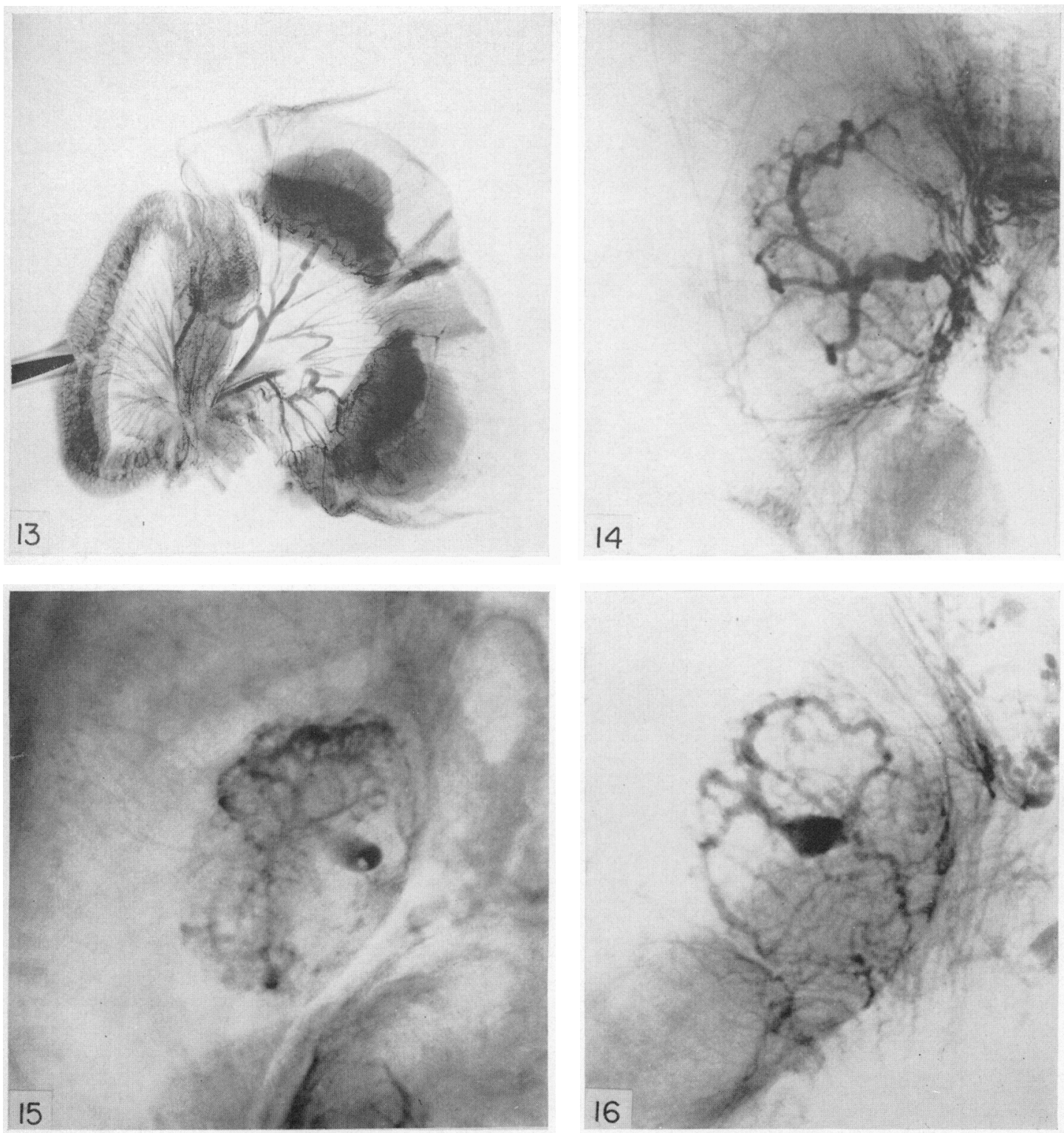

FIG. 13. Unilaterally pregnant uterus, 23 days post coitum, injected with barium sulphate suspension and gelatin. The foetuses were removed before fixation. Although the suspension was injected on the arterial side, it also appears in the veins, including those draining the non-pregnant horn.

FIG. 14. This and following figures show a placenta with a single large arterial unit from a pregnant rabbit, 27 days post coitum. The angiograms were obtained under identical experimental conditions but with the placenta in three different positions. In this case, the feeding artery enters the sinus from above and there is rapid passage of contrast medium to the efferent vessels.

Frg. 15. Same as Fig. 14. The feeding artery enters from below. There is pooling of the contrast medium and a jet of blood from the feeding vessel is seen as a round, non-opaque area.

Fig. 16. Same as Fig. 14. The feeding vessel enters in the horizontal plane. There is some pooling of contrast medium but less than in Fig. 15. 
veins through the myometrium. This is certainly the case regarding the nonpregnant horn of a unilaterally pregnant uterus (Pl. 4, Fig. 13).

\section{Uterine blood flow and circulation times}

At selective catheterization of the urogenital artery, injection of contrast medium was in balance with blood flow at injection rates between 0.10 and $0.50 \mathrm{ml} / \mathrm{sec}$, mean $0.24 \mathrm{ml} / \mathrm{sec}$. This implies a mean total flow through the two urogenital arteries of $29 \mathrm{ml} / \mathrm{min}$, with considerable variation about the mean.

The placental arterial sinuses begin to fill with contrast medium 0.5 to $4.0 \mathrm{sec}$ after the start of injection and the subsequent flow of the medium through the sinuses appears to vary with their spatial orientation (Text-fig. 3; Pl. 4, Figs.

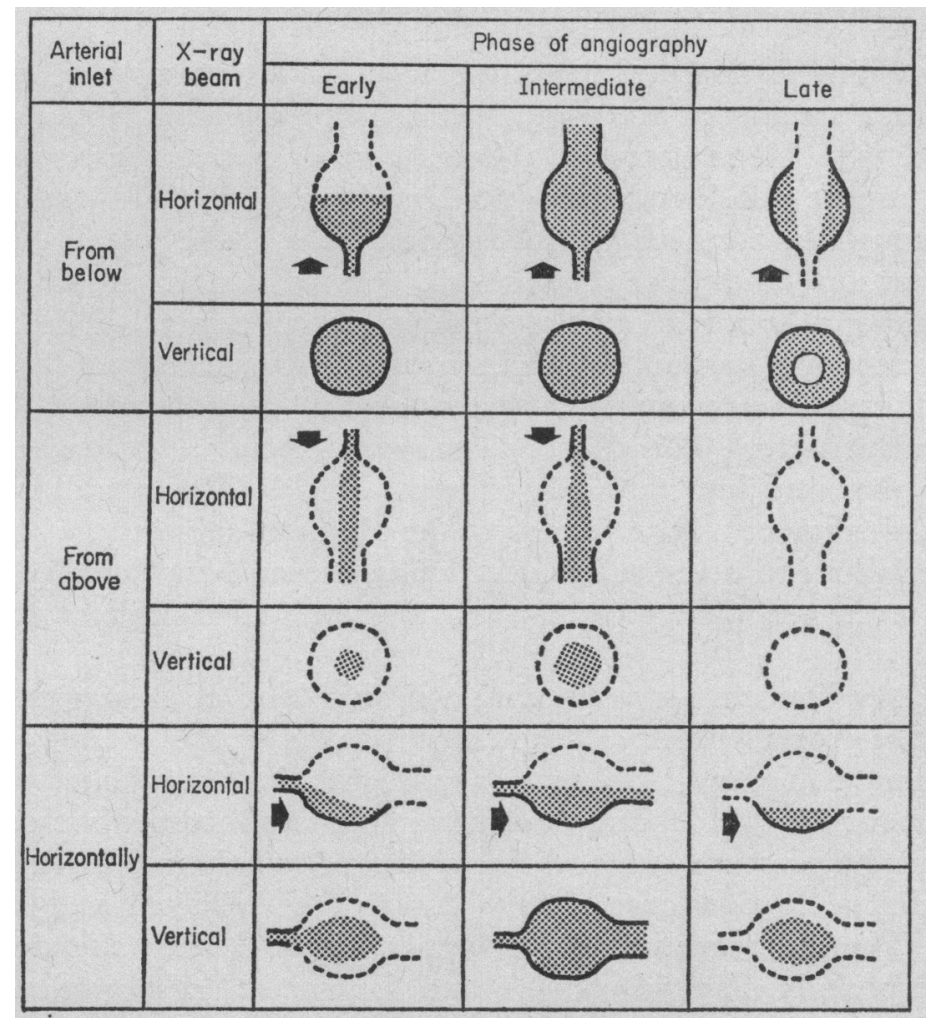

TExT-FIG. 3. The flow of contrast medium through placental arterial sinuses at different spatial orientations. Further explanation in the text.

14 to 16). If the feeding artery enters the sinus from above, the contrast medium rapidly drains through the efferent vessels and the outline of the sinus may be indistinct. If, on the other hand, the feeding artery enters from below, the contrast medium pools because of its high specific density $(=1.32)$ and drains at a slower rate. When the contrast medium disappears from the feeding artery and is replaced by blood, a non-opaque jet can be seen in the sinus (Pl. 2, Fig. 6 ; Pl. 4, Fig. 15). The density of the contrast medium is often higher around the blood jet than at the periphery of the sinus, due to eddies bringing it in along 
the jet. Various intermediate conditions obtain when the feeding artery enters the sinus in the horizontal plane, the rate of filling and emptying with contrast medium then being dependent upon the spatial relations between the inlet and outlet vessels.

The veins draining the myometrium fill sooner and empty faster than those draining the placentae. Contrast medium appears in the former after about 5 to $10 \mathrm{sec}$ and in the latter after about 15 to $45 \mathrm{sec}$ from the start of the injection. It continues to drain through the placental veins long after the myometrial veins have emptied (Pl. 1, Fig. 2), due to pooling in some of the placental arterial sinuses.

\section{DISCUSSION}

The most striking feature of the rabbit placenta is the presence of large arterial sinuses. These structures are probably of haemodynamic importance. Each sinus is fed with blood through a long, narrow and tortuous vessel. Blood pressure must be considerably reduced and pulse pressure damped during passage through the 5 -cm long spiral arteries. Thus, at the entrance to the sinus, the blood pressure and pulse pressure will both be low. In the sinus, however, the cross-sectional area is about twenty times greater than in the feeding artery. In accordance with Bernoulli's equation, the linear velocity of the blood will therefore diminish to an equivalent extent and its lateral pressure will increase (cf. the Venturi meter). This effect will be modified only slightly when the blood flows from the sinus into the wide efferent arteries. The overall effect of this vascular arrangement will be to perfuse the placental labyrinth with blood at a relatively high mean pressure, reduced pulse pressure and low linear velocity. This slow, even perfusion probably provides optimal conditions for placental exchange.

Study of the literature suggests that a similar kind of arrangement exists in the two other orders with discoid, haemochorial placentae, namely the rodents and the primates. Young (1956) made a radiographic study of injected specimens of pregnant rat uteri. He found that the mesometrial arteries narrowed as they approached the placental site and then widened greatly into an arterial plexus from which one or two large arteries entered the placenta and supplied the labyrinth. These observations have been confirmed and extended by other workers, especially Panigel (1959) and Legrand (1968), whose corrosion preparations provide an elegant demonstration of the vascular architecture of the rat placenta.

It is well accepted that the often tightly coiled spiral arteries supplying the human placenta frequently widen before emptying into the intervillous space (Harris \& Ramsey, 1966; Freese, 1968; Wigglesworth, 1969). By means of casts and barium sulphate-gelatin preparations, Wigglesworth (1969) has demonstrated that the basic unit of the human placenta is the foetal lobule. Each lobule is supplied with maternal blood by a single spiral artery, which opens into a sinus-like intralobular space. The blood from the intralobular space perfuses a capillary-like region of closely packed villi and collects in the interlobular spaces from which venous drainage occurs. Thus, from a functional, 
haemodynamic standpoint, there is a close resemblance between the labyrinthine placenta of the rabbit and the villous placenta of man.

The numerous cross connections between the spiral arteries in the uterine wall and the plexus of vessels beneath each placenta may play an important rôle in determining the distribution of uterine blood flow between the myometrium and placentae. In the rabbit, maternal hypoxaemia causes a reduction of maternal placental blood flow, whilst myometrial blood flow is unchanged (Duncan, 1969). Similarly, vasopressin gives a more pronounced decrease of placental than of myometrial blood flow (Carter et al., 1968). On the other hand, we have recently shown that phentolamine administration increases placental blood flow at the expense of myometrial blood flow (Garter \& Olin, in preparation). The proportion of blood going to the placentae may very well be regulated by a sphincter mechanism located in the feeding arteries. Closure of the sphincter would result in shunting of blood through the arterial plexus to the myometrium.

The presence of a sphincter can only be confirmed histologically, but it is obvious that a sphincter-like mechanism must close the feeding arteries at parturition. No leakage of contrast medium occurred at the placental site even when angiography was performed immediately post partum (Text-fig. 2). An arrangement which prevents intra-partum bleeding is, of course, essential in a polytocous mammal, where sustained contraction of the uterine muscle cannot occur until the entire litter has been born. It is also understandable that the undelivered foetus not only waits in position while the other foetuses are born (Garter et al., 1971), but even has a functional maternal placental circulation.

In addition to a possible mechanism for shunting blood away from the placentae, arteriovenous shunts may exist in the uterus. In both pregnant and non-pregnant uterine horns, barium sulphate suspension injected on the arterial side appears in the veins, although the particles are too large to pass capillary vessels or the channels of the placental labyrinth.

The contrast medium used in serial angiography did not cross the placental barrier even after selective injection in the urogenital artery. It may be that contrast medium can pass from the maternal to the foetal circulation in amounts too small to be detected radiographically, but this possibility has never been investigated.

The total flow through the urogenital arteries, estimated by a radiographic technique, is on average $29 \mathrm{ml} / \mathrm{min}$. This includes blood flow to the cranial part of the vagina and to the bladder and, obviously, does not include flow through the tubal branch of the ovarian artery. It should, nevertheless, be possible to take urogenital blood flow as an index of uterine blood flow when dealing with the pregnant animal. Studying the distribution of radioactive microspheres which had been injected into the left ventricle, Duncan (1969) determined mean total uterine blood flow as $31 \mathrm{ml} / \mathrm{min}$ in rabbits 27 to 29 days post coitum. In their classic study of uterine blood flow in pregnant rabbits, Barcroft, Herkel \& Hill (1933) got a maximum value of $30 \mathrm{ml} / \mathrm{min}$. With the support of these figures, angiography would appear to be a valid technique for measuring blood flow in the uterus as well as for demonstrating flow patterns.

Girculation time through the myometrium seemed to be shorter than that 
through the placentae, presumably because of a shorter circuit. Although the discrepancy was no doubt exaggerated due to the replacement of blood by contrast medium, there is probably a true temporal separation of the myometrial and placental circulations. It may be possible to exploit this fact in order to determine the myometrial and maternal placental blood flows separately by a dye dilution technique. Our experience proves that it would be possible to catheterize the urogenital artery for dye injection and to pass a catheter into the uterine vein for sampling of blood.

\section{REFERENCES}

Barcroft, J., Herkel, W. \& Hill, S. (1933) The rate of blood flow and gaseous metabolism of the uterus during pregnancy. F. Physiol., Lond. 77, 194.

Barcroft, J. \& Rothschild, P. (1932) The volume of blood in the uterus during pregnancy. $\mathcal{F}$. Physiol., Lond. 76, 447.

Bengtsson, L. P. (1968) The sponge-tipped catheter-a modification of the open end catheter for recording of myometrial activity in vivo. F. Reprod. Fert. 16, 115.

Garter, A. M., Göthlin, J. \& Bengtsson, L. P. (1968) Effect of vasopressin on the uteroplacental circulation: an angiographic study in the rabbit. F. Reprod. Fert. 17, 419.

Carter, A. M. \& NaAkTgeboren, C. (1970) Über eine kinematographische Methode zum Studium der Uterusphysiologie. Res. Film, 7, 12.

Garter, A. M., Naaktgeboren, C. \& Van Zon-Van Wagtendonk, A. M. (1971) Parturition in the rabbit. Spontaneous uterine activity during late pregnancy, parturition and the post partum period and its relation to normal behaviour. Europ. 7. Obstet. Gynaec. (In press).

Duncan, S. L. B. (1969) The partition of uterine blood flow in the pregnant rabbit. F. Physiol., Lond. $204,421$.

Freese, U. E. (1968) The uteroplacental vascular relationship in the human. Am. F. Obstet. Gynec. 101, 8.

HARRis, J. W. S. \& RAMSEY, E. M. (1966) The morphology of human uteroplacental vasculature. Contr. Embryol. 38, 43.

LiEgRAND, C. (1968) Trophoblaste endovasculaire dans les artères utéroplacentaires de la ratte. Bull. Ass. Anat. Paris, 53, 1170.

Olin, T. \& Redman, H. (1966) Spillover flowmeter. A preliminary report. Acta radiol. (Diag.), 4, 217.

PANiger, M. (1959) Observations sur les rapports anatomiques qui s'établissent au cours du développement entre les circulations maternelles et foetales dans le placenta de certains mammifères. I. Anatomie vasculaire du placenta chez les Rongeurs. C. $r$. Ass. Anat. 46, 565.

WrgGleswORTH, J. S. (1969) Vascular anatomy of the human placenta and its significance for placental pathology. 7. Obstet. Gynaec. Br. Commonw. 76, 979.

Young, A. (1956) The vascular architecture of the rat uterus during pregnancy. Trans, R. Soc. Edinb.63, 167. 